Published as: Oliver, J.J. (2017). Exploring industry level capabilities in the UK Creative Industries. Creative Industries Journal.

DOI: http://dx.doi.org/10.1080/17510694.2017.1282302

\title{
Title: Exploring industry level capabilities in the UK Creative Industries
}

\begin{abstract}
The competitive dynamics of the UK's Creative Industries has changed considerably over the past decade and perhaps none more so than in the Publishing Industry. There is no doubt that this industry continues to undergo structural changes that compel firms to adapt and transform their business in response to the dynamic nature of competitive environment.

Industries have long been examined by researchers from a strategic perspective with various themes of inquiry relating to; industry structure and positioning, industry evolution and development, industry lifecycle, industry change and industry consolidation. This paper argues that 'industry analysis' could usefully draw on Dynamic Capabilities Theory which argues for the strategic adaptation and reconfiguration of firm resources and capabilities in order to address a rapidly changing competitive environment.

This paper will present empirical findings from a comparative time-series analysis (1997-2014) of the UK Publishing Industry and compare it to other industries categorised within the UK's Creative Industries. In doing so, this analysis will add to the limited knowledge base on industry level dynamic capabilities and extend our knowledge on interindustry comparisons in performance following the reconfiguration of industry resources.

Keywords

Creative Industries, Publishing Industry, Dynamic Capabilities, Industry Analysis, Labour Productivity
\end{abstract}

\section{Introduction}

The competitive dynamics of the UK's Creative Industries has changed considerably over the past decade and perhaps none more so than in the Publishing Industry. There is no doubt that this industry continues to undergo structural changes that compel firms to adapt and transform their business in response to the dynamic nature of competitive environment (Oliver, 2013; 2014). In the UK, these structural changes are illustrated by the substantial number of job losses in publishing, from 308,500 in 1997 to 225,000 in 2014. Some of these losses can be attributed to macro environmental events such as the collapse of the dot.com economy in $2000(33,100)$, the advent of new media technologies in $2004(30,900)$ and the Global Financial Crisis of 2008 (33,100). However, it is the disruptive nature of innovative digital technologies on organizational business models, value chains, and profitability that has tended to shape the debate on the strategic adaptation of firms (Kung, 2008; Picard, 2010; Coates Nee, 2013; Schlesinger and Doyle, 2015).

Industries have long been examined by researchers from a strategic perspective with various themes of inquiry relating to; industry evolution and development, industry structure and positioning, industry lifecycle, industry change and industry consolidation. Fundamentally, this body of knowledge emphases the importance of an organisation's strategic fit with their competitive environment to achieve competitive advantage. This paper argues that 'industry analysis' could usefully draw on Dynamic Capabilities Theory (Teece, 
Published as: Oliver, J.J. (2017). Exploring industry level capabilities in the UK Creative Industries. Creative Industries Journal.

DOI: http://dx.doi.org/10.1080/17510694.2017.1282302

Pisano and Shuen, 1997; Teece 2013) which argues for the strategic adaptation and reconfiguration of firm resources and capabilities in order to address a rapidly changing competitive environment. The increasingly dynamic nature of publishing provides an ideal context to examine the notion of industry level dynamic capabilities, and whilst questions of industry analysis have been extensively covered in the field of strategic management, there is a dearth of literature that examines dynamic capabilities at industry level, and more specifically, the UK's Creative Industries.

This paper will present empirical findings from a comparative time-series analysis (1997-2014) of the UK Publishing Industry (which comprises of two employment groups: journalists, newspaper and periodical editors; and authors, writers and translators ${ }^{1}$ ) and compare it to other parts of the UK Creative Industries. Using descriptive and inferential statistics, this research will examine two key resource based metrics: the Number of Employees and the Gross Value Added (£) by each industry.

This paper aims to extend the understanding of industry level dynamic capabilities by examining empirical data. Originally, the Dynamic Capabilities Theory (DCT) was developed to explain firm level differences in sustaining competitive advantage in turbulent environments and this per extends the 'firm level' approach to dynamic capabilities into an 'industry level' concept by examining the UK's Creative Industries.

\section{Literature Review}

The literature on dynamic capabilities continues to evolve, but it is largely fragmented with little in the way of shared consensus of its precise characteristics, nor indeed the development of theoretical frameworks that have been rigorously tested through empirical study. However, the review of literature for this paper argues that DCT describes a phenomenon that has several fundamental components that have consistently featured in studies published in the field. These common themes refer to: organisational adaptation where the focus is on reconfiguring resources, capabilities and competencies; this strategic adaptation of resources aims to produce positive effects on performance; this adaptive process occurs in a compressed timescale due to the fast changing nature of market conditions.

\section{Dynamic capabilities: adapting resources for a rapidly changing environment}

Teece et al $(1997,516)$ seminal paper on dynamic capabilities argued that it was a firm's "ability to integrate, build, and reconfigure internal and external competences to address rapidly changing environments" that explained the fundamental question of how firms achieved competitive advantage and superior performance over time.

The idea that organizations' have dynamic capabilities arose from theorists questioning how firms sustained competitive advantage and superior performance in high velocity conditions where "the increasing dynamism of the environment" (Pettigrew, et al,

\footnotetext{
${ }^{1}$ Department of Culture Media \& Sport, Creative Industries Economic Estimates, January 2015, Statistical Release.
} 
Published as: Oliver, J.J. (2017). Exploring industry level capabilities in the UK Creative Industries. Creative Industries Journal.

DOI: http://dx.doi.org/10.1080/17510694.2017.1282302

2007, 143) made it increasingly difficult to remain competitive. Many scholars (Leavy, 1998; Zollo and Winter, 2002; Helfat and Peteraf, 2015) concluded that superior performance is driven by a firm's ability to learn, adapt and change their resource configuration in order to produce a series of temporary competitive advantages over time. Lawton and Rajwani (2011, 167) took this line of thinking further and concluded that "dynamic capabilities are the bridge between firm resources and business context" and as such, this concept provided a useful lens through which to examine how media firms adapted their resource base to produce new capabilities and subsequent superior organizational performance.

In its simplest form 'dynamic capabilities' is a consideration of the adaptation of firm resources and capabilities in relation to structural changes in market conditions. It suggests that tangible resources are configured and utilised to generate value and rents, and that intangible resources in the form of skills, experience, learning, systems and processes create competitive advantages that cannot easily be imitated by competitors. Ambrosini and Bowman (2009, 30-35) argued that dynamic capabilities "specifically focuses on how firms can change their valuable resources over time". They go on to argue that the words dynamic capabilities refer to the drive and enthusiasm of a firm in their "renewal of resources". This perspective echoes the earlier work of Teece and Pisano (1994), Zollo and Winter (2002), Malhotra and Hinings (2013) who emphasised that a changing external environment required firms to adapt and reconfigure resources, assets, operating routines and competencies in order to improve their effectiveness and competitiveness in the pursuit of superior performance. In a sense, the idea that firm capabilities need to be 'dynamic' is a consideration of the competitive environment, its future direction, and how a firm can take advantage of the opportunities provided in their existing and future markets.

Many industries have changed and evolved over the past decade due to high velocity market conditions that are characterised by a blurring of industry boundaries, new industry entrants and changing business models. As such, the argument for the strategic adaptation and reconfiguration of firm resources and capabilities seems well founded. Indeed, Hensman et al $(2013,10)$ noted that corporate strategies have historically had competitive advantage at their core, however, due to the dynamic nature of the digital media environment the "only advantage is the ability to change more quickly than one's rivals" to the extent that corporate strategies need to emphasise organizational adaptation, or as they put it, "dynamic capabilities on steroids". They also argued that researchers have largely ignored the notion of how to move dynamic capabilities from theory into implementable practice. This criticism, is to an extent justified, particularly as Dixon et al $(2014,186)$ referred to dynamic capabilities as a "black box" with unknown contents. However, the recent work by Oliver (2014) presented a conceptual framework which focussed on specific variables that could be attributed to dynamic capabilities traits and applied these to UK media firms in a longitudinal analysis of dynamic capabilities and superior firm performance. This work argued that organisations' can renew, refresh and leverage new capabilities and competencies in order to successfully adapt to turbulent markets conditions by setting corporate objectives and implementing a strategy that:

- $\quad$ is aspirational and stretches the organisation in to winning position in the market place; 
Published as: Oliver, J.J. (2017). Exploring industry level capabilities in the UK Creative

Industries. Creative Industries Journal.

DOI: http://dx.doi.org/10.1080/17510694.2017.1282302

- acknowledges the need to form strategic alliances, merge or acquire other firms' capabilities rather than rely on organic development of new capabilities;

- absorbs research and development costs for a sustained period of time;

- directs significant resource commitments in infrastructure, people and organisational processes in order to develop innovative responses to structural market changes;

- emphasises resource investment in new products and services.

\section{Dynamic capabilities at industry level}

The increasingly dynamic nature of the digital media environment provides an ideal context to examine the dynamic capabilities exhibited by a group of organisations competing in a high velocity environment that is characterised by ambiguity and complexity (Kung, 2008; Lee, 2010). As a consequence "firms have naturally adapted their business and corporate strategies in the face of these changes" (Doyle, 2013, 35) to the extent that industry level capabilities could be considered to be converging. Whilst questions of industry analysis have been extensively covered in the field of strategic management, there is a dearth of literature that examines dynamic capabilities from an industry level perspective.

The idea that an industry can exhibit dynamic capabilities has been investigated by a relatively small number of researchers. For example, Zott (2003) developed a theoretical model that explained intra-firm differences in performance within the same industry, whilst Owers and Alexander (2011) longitudinal examination of media industries found that new media technologies and media ownership acted as key drivers for media organisations' to transform and restructure of their resource base. However, the work of Lampel and Shamsie (2003, 2191), which examined the evolution of capabilities in the Hollywood movie industry, is of particular interest in terms of supporting the idea of industry level capabilities. They found that a highly turbulent competitive environment created "new patterns of competition" within the industry and "new managerial mindsets" which tended to dominate what was considered to be new industry level capabilities. In particular, they argued that new capabilities emerged in the form of 'mobilizing capabilities' which "consists of routines needed to identify and commit most of the resources, particularly in the form of various forms of creative talent such as producer, director, writer, and stars" and 'transforming capabilities' that "comprises routines that drive and regulate the process of using this bundle of resources to obtain a finished product of a desirable quality".

This evolutionary view of industry level capabilities is supported by Eisenhart and Martin (2000) and De Witt and Mayer (2005) who argued that the emergence of new industry capabilities was determined by two factors. Firstly, that a series of incremental innovations in products and services lead to widespread imitation within the competitive set. Teece et al (1997, 526) supported this view arguing that challenger firms simply reproduced the "strategic position" of market leading firms who had achieved a competitive advantage. Deans et al (2002) and Pettigrew et al $(2007,39)$ noted that the converging nature of industry level capabilities essentially produced new capabilities that could be considered as the 'minimum threshold' that were required to satisfy market requirements. Secondly, these new industry level capabilities could be developed by firms competing independently of each other, but that they ultimately converged due to the limiting factors of technological 
Published as: Oliver, J.J. (2017). Exploring industry level capabilities in the UK Creative Industries. Creative Industries Journal.

DOI: http://dx.doi.org/10.1080/17510694.2017.1282302

capability and regulation within the industry. Madhok and Osegowitsch $(2000,328)$ provided a different perspective on the emergence of industry level capabilities. They argued that it was collaborative activity in the form of strategic alliances between competitive rivals who possessed "complementary skills" and sought to reduce the risks inherent in the innovation process that led to a convergence of industry level capabilities.

\section{Positioning this research}

More than two decades of technological and social change has resulted in an increasingly dynamic media environment. This type of competitive context provides an interesting setting to examine the theory on dynamic capabilities, since high velocity market conditions drive organisations to adapt and renew resources that produce new capabilities, maintain competitiveness and deliver superior performance.

This paper aims to investigate dynamic capabilities and superior performance at industry level by examining the UK Creative Industries, as a whole, and inter-industry performance within this broad categorisation. Whilst the creative industries have been one of the successes of the UK economy in recent times, the job losses previously discussed in the Publishing Industry suggests that each of the sub-industries are likely to have performed in different ways.

As previously mentioned, there are a limited number of studies that have examined the notion of industry level dynamic capabilities (Lampel and Shamsie, 2003; Zott, 2003; Owers and Alexander, 2011;) and so the findings presented in this paper will extend our knowledge on industry level dynamic capabilities, inter-industry performance and provide an insight into how the UK Publishing Industry has adapted and evolved to digital media over two decades change and turbulence.

\section{Method}

The aim of this research was to investigate the existence of industry level dynamic capabilities and superior performance in the UK's Creative Industries, and with a specific emphasis on the Publishing Industry. To achieve this, two key resourced based economic variables were used as units of analysis. Firstly, since the size of the labour force in each industry is likely to contribute a significant amount to the total costs of industry resources, the 'Number of Employees' (NE) in each industry provides an important economic indicator. Secondly, 'Gross Value Added' measures the contribution to the economy of each individual industry measures the economic contribution in terms of the value of goods and services that each industry has made to the UK Creative Industries. Both of these units of analysis were further combined to provide annualised figures for 'GVA per Employee ( $£$ )' which was used as an indicator of superior performance as consequence of reconfiguring human resources.

The specific research objectives were:

RO1 - To examine how the UK Creative Industries have reconfigured human resources and produced positive effects on performance over time. 
Published as: Oliver, J.J. (2017). Exploring industry level capabilities in the UK Creative

Industries. Creative Industries Journal.

DOI: http://dx.doi.org/10.1080/17510694.2017.1282302

RO2 - To examine how the UK Publishing Industry has reconfigured human resources and produced positive effects on performance performed over time.

RO3 - To examine how UK Publishing Industry has performed compared other parts of the UK Creative Industries.

\section{Method}

The quantitative method of 'time series analysis' provided the most appropriate way to identify dynamic capabilities and superior performance over time since it could identify patterns in historical data. The methodological approach used 'Year' (1997-2014) as independent variable, and the 'Number of Employees' (NE) and 'Gross Added Value' (GVA) as dependent variables. The data was obtained from the Department of Culture Media \& Sport website (www.gov.uk) which hosts a number of publications relating to the creative industries. In essence, the historical data used in this research was obtained from a number of reports entitled Creative Industries Economic Estimates from the years 2016, 2015, 2011, 2010, 2007 and 2006.

Time series analysis is useful in a number of ways. It can identify trends in NE and GVA over time, cyclicality in the industry or wider economy, and irregular events which can produce deviations from the general trend. The collapse of the dot.com economy in 2000, the advent of new media technologies in 2004 and the Global Financial Crisis which emerged in 2007, which have previously been mentioned, are good examples of irregular events that have produced variations in the trend data.

Time series analysis also has an obvious drawback, that of the standardisation and (in)consistency in the data due to changes in the methodological approach used to collect and categorise the data over time. The data collected in this paper was also subjected to the vagaries of this issue. Indeed, the Department of Culture Media \& Sport recognise this problem in their reports and state that they have been working with the Office for National Statistics on Standard Occupational and Industrial Classification Codes.

They further add that the NE data has been taken from Annual Population Survey and GVA data from the Annual Business Survey. Having said that, whilst it has been possible to

access employment data for the 'aggregate' of the Creative Industries over the period 1997-2014, it has been impossible to replicate this data for sub-industries (eg. Publishing; Film \& TV; Music, Performing \& Visual Arts). However, employment data does exist for what is called the 'Creative Economy' which is defined as the contribution of those people who are in creative occupations inside and outside of the creative industries.

Ideally, this analysis would have benefitted from a like for like comparison of NE and GVA for the Creative Industries. Instead, the data used in this research was NE in the Creative Economy and GVA in the Creative Industries. Since, since the findings of this research are descriptive and illustrative it is possible to broadly consider the GVA per Employee data since large proportion of the jobs in the lie in the creative industries and not 
Published as: Oliver, J.J. (2017). Exploring industry level capabilities in the UK Creative Industries. Creative Industries Journal.

DOI: http://dx.doi.org/10.1080/17510694.2017.1282302

the creative economy. For example, in 2014 there were $2.75 \mathrm{~m}$ jobs in the Creative Economy, of which, $1.81 \mathrm{~m}$ jobs were in the Creative Industries ${ }^{2}$.

In terms of the two dependent units of analysis used to identify dynamic capabilities and superior performance at industry level, the NE refers to the number of jobs, rather than the number of people in the Creative Economy. This means that main jobs and second jobs, and full and part time jobs are counted equally. Therefore, the NE equates to the number of jobs, rather than the number of people who work in the Creative Economy. As for the second unit of analysis, GVA is used by the Office of National Statistics as the standard metric used measure the contribution of industries to the UK economy. As such, it can be used to compare performance across a number of different industries, and so, this makes conjecture about superior GVA performance easier to justify. It should also be noted that GVA calculated in current prices and not adjusted for the effects of inflation and is closely aligned to another standard measure of economic performance, that of Gross Domestic Product (GDP). Since GDP is calculated as GVA + taxes on products - subsidies on products. Therefore, GVA provides a better measure of the contribution of that individual industry makes to the Creative Industries and to the UK economy.

Finally, not all of the creative industries included in the Creative Industries Economic Estimates have been included in this research, primarily because of significant inconsistencies in the standard industry and occupation classification codes. Consequently, the Crafts and Museum and Galleries industries have been excluded from this analysis.

\section{Data Analysis}

Descriptive statistics were used to describe and summarize the data, and to present meaningful information about resource reallocation in the workforce and GVA performance over time. As such, the analysis is presented in a time series of averages and percentages in relation to the Number of Employees and Gross Value Added and Gross Added Value per Employee (see Appendix 1).

The disadvantage of using descriptive statistics is that the information gleaned from the data is that the results cannot be generalised to any other industry or industries. Having said that, the findings of this research could be considered by future researchers in this field when designing research studies of greater scale and complexity, where the aim would be to reach conclusions on industry level dynamic capabilities that are generalisable to the wider population of industries.

The author has also used data validation checks where possible. For example, any uncertainty presented in the Creative Industries Economic Estimates reports have been referred back to statisticians at the 'Evidence and Analysis Unit' at the Department for Culture Media \& Sport. Secondly, an independent statistician has also been used to advise on issues of data consistency and analysis. In essence, the researcher has made every effort to ensure that the data and analysis presented in this paper is trustworthy and valid. 
Published as: Oliver, J.J. (2017). Exploring industry level capabilities in the UK Creative Industries. Creative Industries Journal.

DOI: http://dx.doi.org/10.1080/17510694.2017.1282302

\section{Data Analysis}

To examine how the UK Creative Industries has reconfigured human resources and produced positive effects on performance over time.

The Creative Industries has been one of the successes of the UK economy. Over the past 20 years the contribution made by firms within these industries has increased from $3.96 \%$ ( $£ 31,205 \mathrm{~m})$ to $5.20 \%(£ 84,067 \mathrm{~m})$ of the total UK economy. The number of employees working in these industries has also increased by 94\%, from 931,000 in 1997 to 1,808,000 in 2014. These statistics are largely well known and documented by various agencies, consultancies and scholars.

But how do these statistics translate into the theory on dynamic capabilities and superior performance over time? Firstly, we see a group of creative industries that are subject to the same macro-environment forces in terms of shifting economic conditions, technological change and disruption in the form of digitalization and new media. Secondly, and from an aggregated point of view, we see the 'Creative Industries' adapt and increase resources in the form of the workforce substantially between 1997-2014.

Thirdly, this strategic adaption of industry human resources should produce positive effects on industry performance. The data indicates a number of positive performance effects over time. For example, we see Total GVA making consistent annual increases to the UK economy of $169 \%$ between 1997-2014. In addition, the GVA per Employee has risen by $39 \%$ from $£ 33,518$ in 1997 to $£ 46,497$ in 2014.

Recent discussions on the UK economy, from a number of political and economic sources, have centred on the issue of high levels of employment, but relatively low levels of productivity following the Global Financial Crisis of 2007-11. Indeed, this question is equally relevant to the creative industries, where GVA Per Employee has yet to recover from the peak of $£ 53,542$ in 2008. Whilst there has been a strong recovery in Total GVA and the Number of Employees between 2009-14, at 46\%, and 26\% respectively, the GVA per Employee has only increased by $15 \%$ over the same period. In essence, this trend equates to a productivity gap within the Creative Industries that has been sustained between 2009-14 (see Figure 1 below).

Whilst productivity gaps tend to be discussed in terms of output per employee between one country and another, it is not unreasonable to consider it in terms of industry and inter-industry analysis, particularly when considering the premise of dynamic capabilities and superior performance. In many ways these lower levels of GVA per Employee and concerns over productivity are to expected since the sustained harshness of macro-economic conditions, created by the Global Financial Crisis, will have affected business capital expenditure, investment in research and development, skills training, and a lack of competition in the market place. 
Published as: Oliver, J.J. (2017). Exploring industry level capabilities in the UK Creative Industries. Creative Industries Journal.

DOI: http://dx.doi.org/10.1080/17510694.2017.1282302

Figure 1: Creative Industries: GVA and GVA per Employee

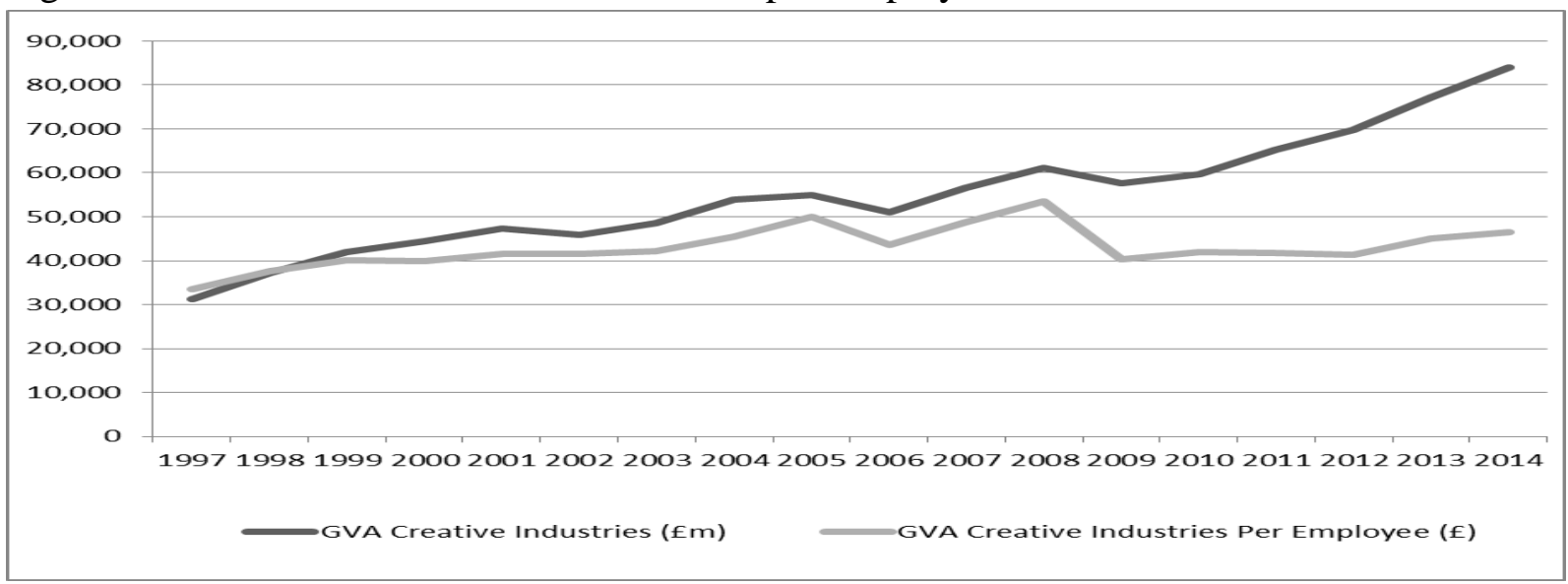

\section{To examine how the UK Publishing Industry has reconfigured human resources and produced positive effects on performance performed over time.}

The strategic adaptation and renewal of resources at industry level, is perhaps, most visibly demonstrated in the structural changes of the workforce. The UK Publishing Industry illustrates these changes more than any other with significant job losses as a result of extraordinary changes in the macro-environment. These include: the collapse of the dot.com economy in 2000 which resulted in 33,100 job losses; the disruption caused by new media technologies in 2004 which resulted in $-30,900$ job losses; and the initial effects of the Global Financial Crisis which resulted in 33,100 job losses in 2008 . Whilst there have been job gains following these events $(+9,400$ in $2001 ;+18,400$ in $2003 ;+16,400$ in $2006 ;+19,000$ in 2012), the net number of job losses between 1997-2014 equates to an astonishing 83,500.

However, in terms of Dynamic Capabilities Theory, the strategic adaption of human resources has delivered superior performance in terms of productivity. For example, there have been consistent increases in GVA per Employee, which has risen from $£ 20,554$ in 1997 to $£ 45,244$ in 2014 ( $+120 \%)$. Whilst the human cost of these job losses is incalculable, from an economic point of view, the long-term reduction in the workforce has delivered vastly improved results in terms of productivity within the industry. In terms of Dynamic Capabilities Theory, UK Publishing has undergone the structural adaptation and reconfiguration of a prime resource component, its workforce, due to the changing nature of the market, which in turn has produced positive effects on economic performance at industry level (see Figure 2 below). 
Published as: Oliver, J.J. (2017). Exploring industry level capabilities in the UK Creative Industries. Creative Industries Journal.

DOI: http://dx.doi.org/10.1080/17510694.2017.1282302

Figure 2: UK Publishing Industry performance over time

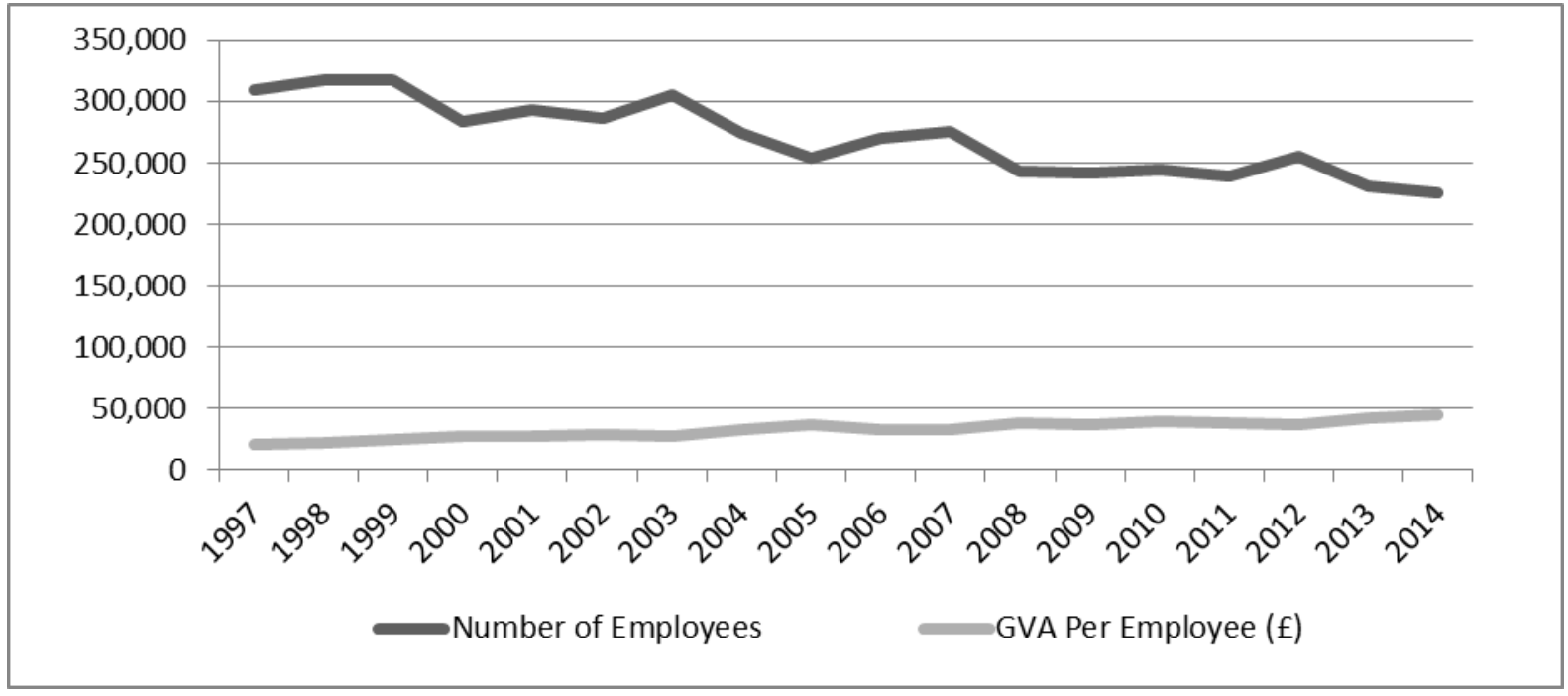

To examine how UK Publishing Industry has performed compared other parts of the UK Creative Industries.

The previous discussion has set out a context to consider the strategic environment, the adaptation of industry (human) resources and performance effects within the Creative Industries and more specifically the Publishing Industry. However, in terms of discussing dynamic capabilities and industry level capabilities and comparative performance effects, we need to consider how publishing has performed in relation to other industries that are classified as 'creative'.

Figure 3 below illustrates the inter-industry GVA per Employee (£) performance based on comparative figures for the year ending 1997 and 2014. Here we clearly see that the Publishing Industry has by far outperformed any other industry, by increasing the GVA Per Employee from $£ 20,554$ to $£ 45,244(+120 \%)$. The next best performance is seen in the Architecture Industry which has increased GVA Per Employee from $£ 14,530$ to $£ 30,252$ $(108 \%)$ and IT, Software and Computer Services where GVA Per Employee increased from $£ 25,952$ to $£ 41,995$ (62\%). The worst performing industry was Film, TV,Video and Radio where GVA increased by $56 \%$, from $£ 5,985 \mathrm{~m}$ to $£ 10,807 \mathrm{~m}$ and the number of employees increased $63 \%$, from 161,800 to 264,000 . The result was a modest increase in GVA per Employee of $11 \%$ from $£ 36,990$ to $£ 40,936$. 
Published as: Oliver, J.J. (2017). Exploring industry level capabilities in the UK Creative Industries. Creative Industries Journal.

DOI: http://dx.doi.org/10.1080/17510694.2017.1282302

Figure 3: Inter-Industry GVA per Employee Performance (1997 and 2014)

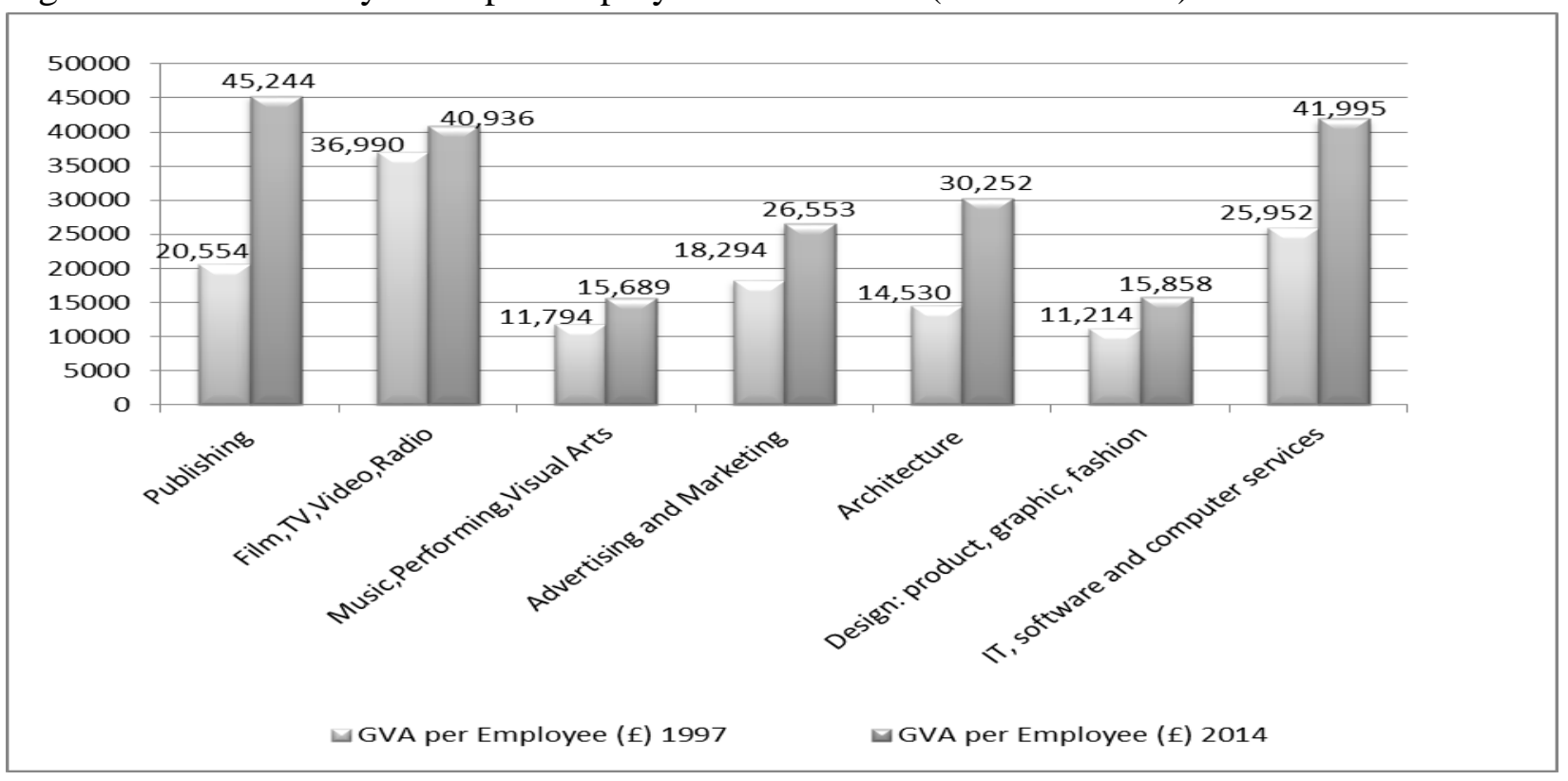

What these figures indicate is that at two points in time, 1997 and 2014, the GVA per Employee performance in publishing has by far exceeded peer creative industries. However, if we take a time series view of the data and look at the 'average' GVA per Employee for each of the years between 1997 and 2014 we see that publishing has a figure of $£ 45,976$ which is less than the top two performing industries which were Architecture $(£ 62,161)$ and IT, Software and Computing (£54,378) (see Figure 4).

Figure 4: Inter-Industry ‘Average’ GVA per Employee (£) Performance over time

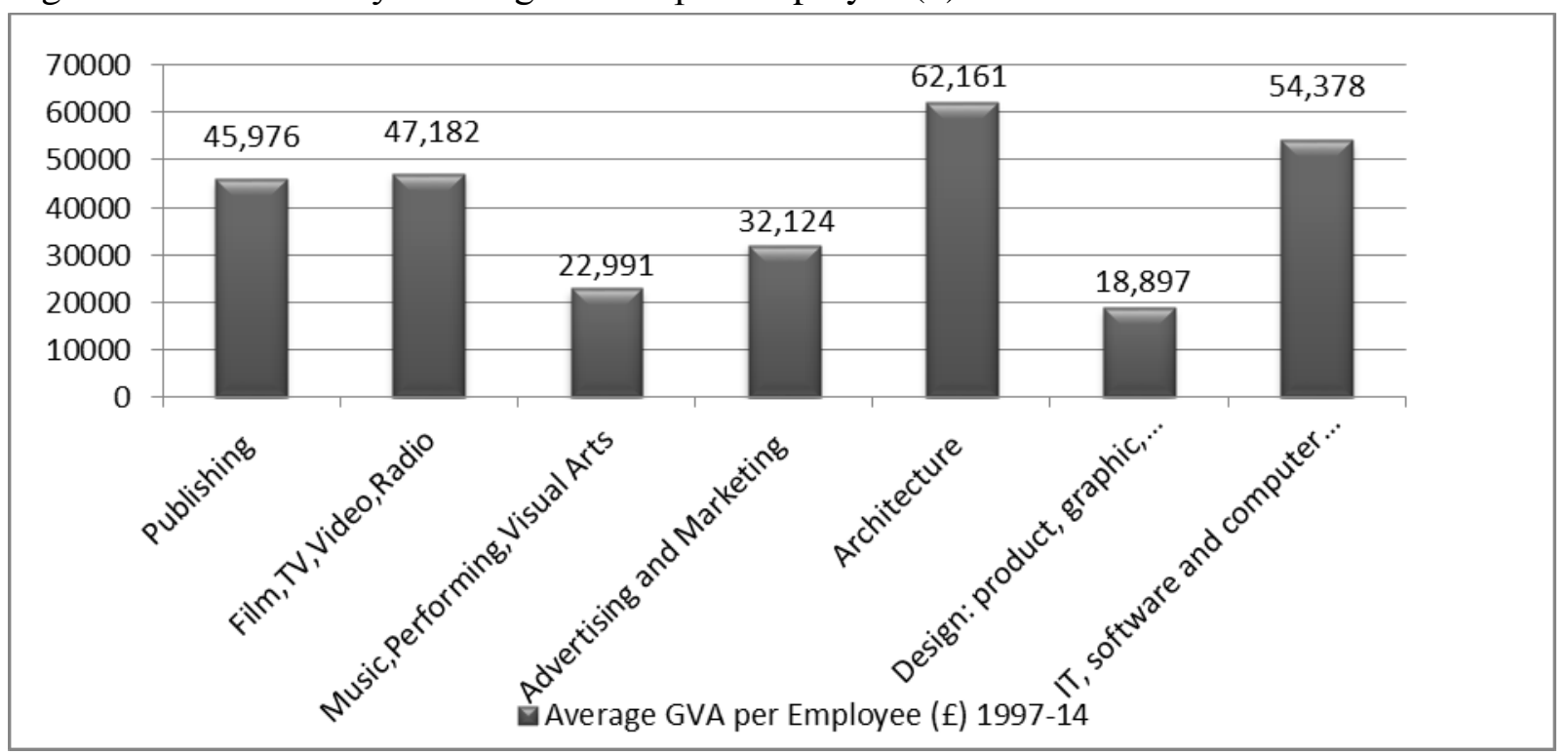


Published as: Oliver, J.J. (2017). Exploring industry level capabilities in the UK Creative Industries. Creative Industries Journal.

DOI: http://dx.doi.org/10.1080/17510694.2017.1282302

In all instances, with the exception of publishing, the number of employees in each industry increased between 1997-2014. In effect, the increasing Publishing Industry GVA and decreasing number of employees, has produced an structural adaptation in the industry and the workforce that has resulted higher far higher levels of productivity in comparison to peer industries.

\section{Conclusions}

The aim of this paper was to extend the limited knowledge on industry level dynamic capabilities and inter-industry performance. As mentioned previously, Dynamic Capabilities Theory (DCT) proposes that resources need to be reconfigured in order to produce new capabilities and competencies, which in turn, yield positive effects on performance. It also argues that this strategic adaption of resources occurs in a compressed timescale due to the fast changing nature of market conditions. So what can we conclude about DCT from the analysis presented in this paper?

Firstly, we can conclude that the UK Publishing Industry provided an ideal context to examine DCT due to a transformative context, driven by an increasingly digital media environment, that has created turbulence and acted as a key driver for the reconfiguration of human resources and resultant structural industry change. This structural adaption of human resources, perhaps surprisingly, has produced positive effects on industry performance. For example, whilst the industry has contracted in terms the number of employees, this reconfiguration of human resource has resulted in a far more productive labour force in terms of GVA per Employee. In terms of DCT we can conclude that the UK Publishing Industry has been more 'dynamically capable' at adapting and reconfiguring their human resources than their peer creative industries to the extent that they have produced superior performance effects in the firm of GVA per Employee.

Secondly, this paper has also been able to draw from DCT to develop our existing knowledge on intra-industry performance and extend it into inter-industry performance comparisons. We have seen that the UK Creative Industries, as a whole, have increased its human resources significantly over the period 1997-2014 and yet this investment has lead to varying degrees of success in terms of performance effects. On the positive side, we have total GVA in the Creative industries increasing on an annual basis, and GVA per Employee rising significantly between 1997 and 2014. However, GVA per Employee peaked in 2008 and whilst there has been significant investment in human resources in the form of the number of employees between 2008-2014, the return on this investment has not yielded significant increases in GVA per Employee. So much so, that the data presents a strong argument for weak levels of performance in terms of human resource (labour) productivity. However, within this broad contextual setting, the sub-industries have produced a variety of GVA per Employee performance effects which provide the basis for inter-industry performance comparisons.

Thirdly, DCT argues that resources need to be rapidly renewed in order to adapted to fast changing market conditions. The implication here is that market turbulence is transient. What the analysis presented in this paper has demonstrated is that the UK Publishing Industry has been exposed to a long period of environmental turbulence and structural industry 
Published as: Oliver, J.J. (2017). Exploring industry level capabilities in the UK Creative Industries. Creative Industries Journal.

DOI: http://dx.doi.org/10.1080/17510694.2017.1282302

change. These conditions have been consistently 'dynamic' unlike other industries that have gone through periods of incremental transition or punctuated adaptation to the digital environment. Future researchers in the field of dynamic capabilities may therefore wish to consider focussing their research on the timescales involved in resource adaptation. In this way, we may get a better understanding of the 'dynamic adaption' of resources in comparison to the 'incremental adaptation' of resources, and how both types of adaptation produces superior performance effects.

\section{Footnotes}

${ }^{1}$ Department of Culture Media \& Sport, Creative Industries Economic Estimates, January 2016, Statistical Release.

2 Department of Culture Media \& Sport, Creative Industries Economic Estimates, January 2016, Statistical Release

\section{REFERENCES}

Ambrosini, Véronique and Cliff Bowman. "What are dynamic capabilities and are they a useful construct in strategic management?." International journal of management reviews 11, no. 1 (2009): 29-49.

Coates, Rebecca Nee. "Creative destruction: An exploratory study of how digitally native news nonprofits are innovating online journalism practices." International Journal on Media Management 15, no. 1 (2013): 3-22.

Danneels, Erwin. "The dynamics of product innovation and firm competences." Strategic management journal 23, no. 12 (2002): 1095-1121.

Deans, Graeme K., Fritz Kroeger, and Stefan Zeisel. "The consolidation curve."

Harvard Business Review, (2002): 20-21.

De Wit, Bob, and Ron Meyer. Strategy synthesis: Resolving strategy paradoxes to create competitive advantage: Text and readings. Cengage Learning EMEA, 2010.

Dixon, Sarah, Klaus Meyer, and Marc Day. "Building dynamic capabilities of adaptation and innovation: a study of micro-foundations in a transition economy." Long Range Planning 47, no. 4 (2014): 186-205.

Doyle, Gillian. Understanding media economics. SAGE Publications Limited, 2013. Eisenhardt, Kathleen M., and Jeffrey A. Martin. "Dynamic capabilities: what are they?." Strategic management journal 21, no. 10-11 (2000): 1105-1121.

Helfat, Constance E., and Margaret A. Peteraf. "Managerial cognitive capabilities and the microfoundations of dynamic capabilities." Strategic Management Journal 36, no. 6 (2015): 831-850.

Hensmans, Manuel, Gerry Johnson, and George Yip. Strategic transformation: changing while winning. Springer, 2012.

Küng, Lucy. Strategic management in the media: Theory to practice. Sage, 2008.

Lampel, Joseph, and Jamal Shamsie. "Capabilities in motion: New organizational forms and the reshaping of the Hollywood movie industry." Journal of Management Studies 40, no. 8 (2003): 2189-2210.

Lawton, Thomas, and Tazeeb Rajwani. "Designing lobbying capabilities: managerial choices in unpredictable environments." European Business Review 23, no. 2 (2011): 167-189. 
Published as: Oliver, J.J. (2017). Exploring industry level capabilities in the UK Creative Industries. Creative Industries Journal.

DOI: http://dx.doi.org/10.1080/17510694.2017.1282302

Leavy, Brian. "The concept of learning in the strategy field review and outlook." Management Learning 29, no. 4 (1998): 447-466.

Lee, Ya-Ching. "Business Process Reengineering Within the Media Industry in Taiwan." International Journal on Media Management 12, no. 2 (2010): 77-91.

Madhok, Anoop, and Thomas Osegowitsch. "The international biotechnology industry: a dynamic capabilities perspective." Journal of International Business Studies 31, no. 2 (2000): 325-335.

Malhotra, Namrata, and CR Bob Hinings. "Unpacking continuity and change as a process of organizational transformation." Long Range Planning 48, no. 1 (2015): 1-22.

Oliver, John J. "Media management tools: UK broadcast media executives' perspective." International Journal on Media Management 15, no. 4 (2013): 245-257.

Oliver, John J. "Dynamic capabilities and superior firm performance in the UK media industry." Journal of Media Business Studies 11, no. 2 (2014): 57-78.

Owers, James, and Alison Alexander. "Market reactions to merger, acquisition, and divestiture announcements in the media industries." International Journal on Media Management 13, no. 4 (2011): 253-276.

Pettigrew, Andrew M., Howard Thomas, and Richard Whittington, eds. Handbook of strategic management. Sage, 2007.

Picard, Robert G. "Value creation and the future of news organizations: Why and how journalism must change to remain relevant in the twenty-first century." (2010).

Schlesinger, Philip, and Gillian Doyle. "From organizational crisis to multi-platform salvation? Creative destruction and the recomposition of news media." Journalism 16, no. 3 (2015): 305-323.

Teece, David J. "The foundations of enterprise performance: Dynamic and ordinary capabilities in an (economic) theory of firms." The Academy of Management Perspectives 28, no. 4 (2014): 328-352.

Teece, David J., Gary Pisano, and Amy Shuen. "Dynamic capabilities and strategic management." Strategic management journal (1997): 509-533.

Teece, David, and Gary Pisano. "The dynamic capabilities of firms: an introduction." Industrial and corporate change 3, no. 3 (1994): 537-556.

Winter, Sidney G. "Understanding dynamic capabilities." Strategic management journal 24, no. 10 (2003): 991-995.

Zollo, Maurizio, and Sidney G. Winter. "Deliberate learning and the evolution of dynamic capabilities." Organization science 13, no. 3 (2002): 339-351. 
Published as: Oliver, J.J. (2017). Exploring industry level capabilities in the UK Creative Industries. Creative Industries Journal.

DOI: http://dx.doi.org/10.1080/17510694.2017.1282302

Zott, Christoph. "Dynamic capabilities and the emergence of intra-industry differential firm performance: insights from a simulation study." Strategic management journal 24, no. 2 (2003): 97-125. 